\title{
RACIONALIZAÇÃO DOS SISTEMAS ADMINISTRATIVOS
}

"O campo dos sistemas é parte essencial do trabalho do administrador. Todo dirigente é responsável pelos procedimentos que seus subordinados adotam." - WILLIAM A. GILL

"Todos os setores administrativos - produção, compras e relaçóes industriais - compreendem rotinas, sistemas e procedimentos que transformam em ação as diretrizes da diretoria." - JOHN W. HASLETT

O conjunto de documentos, procedimentos, equipamentos e os próprios funcionários que constituem uma função administrativa denomina-se "sistema". Tôdas as organizações possuem numerosos sistemas necessários ao desempenho de suas funções, como, por exemplo, os sistemas de compras, o de recebimento de matérias-primas, o de pagamento das contas.

Maior rapidez no trâmite das informações, economias de mão-de-obra e de material, maior exatidão, enfim, melhorias gerais de eficiência são obtidas dando-se a devida atenção às rotinas burocráticas, através da eliminação de tarefas inúteis e da reorganização das tarefas necessárias.

Existe para aperfeiçoar a estática dos formulários — isto é, o seu conteúdo e a sua disposição gráfica - um conjunto de regras. ${ }^{1}$ Há, também, uma série de principios visando

Claude Machline - Professor-Ajunto do Departamento de Administração da Pradução, da Escola de Administração de Emprêsas de São Paulo.

1) Vide: Claude Machrine, "Racionalização de Formulários", Revista do Administração de Emprêsas, vol. 4, n. ${ }^{\circ} 12$, setembro de 1964. 

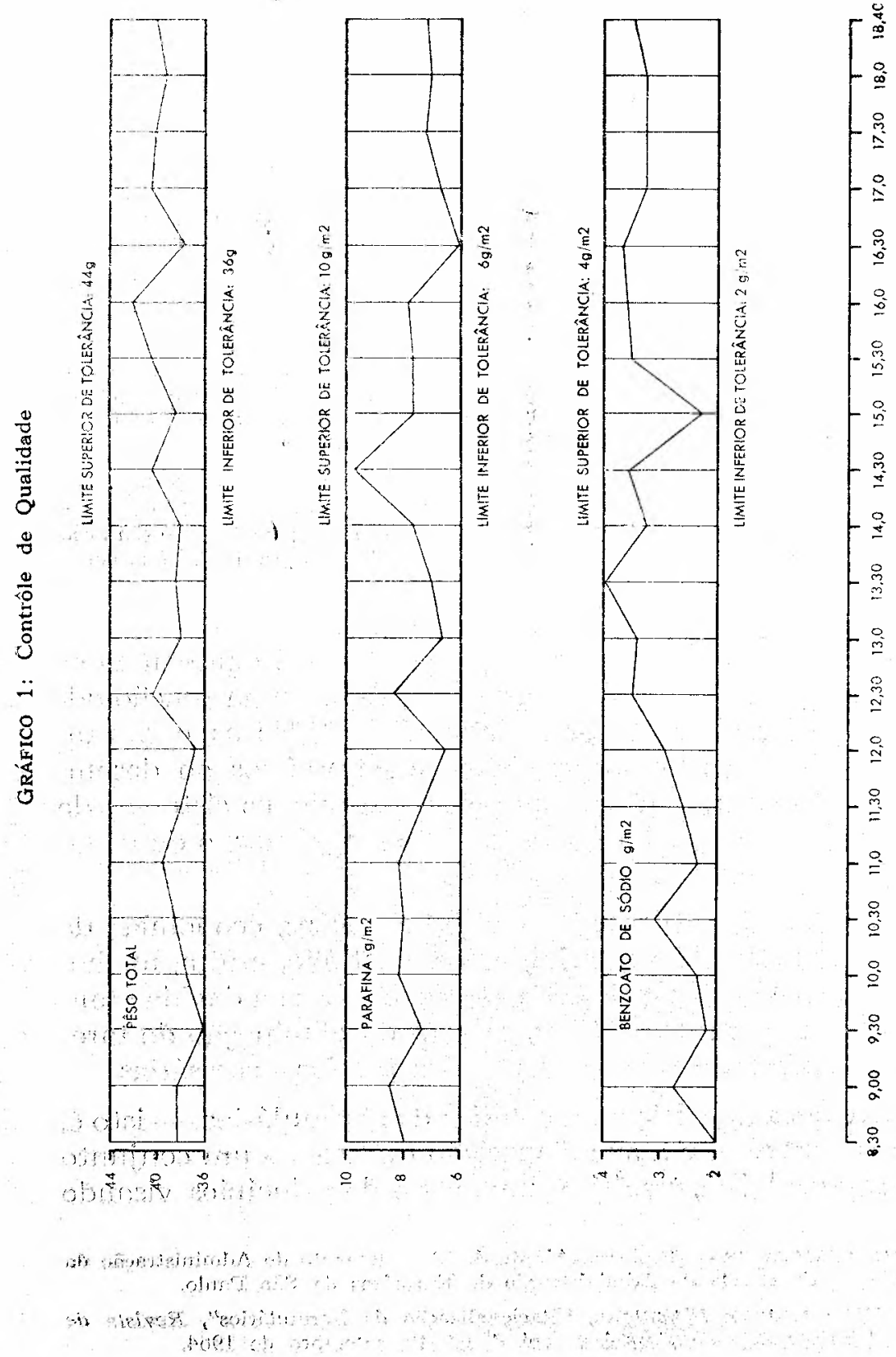
à racionalização de sua dinâmica. Êsses princípios, frutos da observação e do bom senso, serão expostos neste artigo em relação, sucessivamente, ao preenchimento, à circulação e ao arquivamento dos documentos.

\section{PREENCHIMENTO DOS DOCUMENTOS}

Ainda que um formulário tenha sido corretamente idealizado sob o ângulo dos elementos que o compõem papel, texto, disposição gráfica —, o administrador deverá certificar-se de que os funcionários o estão preenchendo de maneira legível e rápida, a fim de que a informação seja transmitida em tempo mínimo e os funcionários obtenham o rendimento máximo.

Será proveitoso que o administrador verifique o cumprimento das normas expostas adiante:

- Evitar palavras supérfluas - As redundâncias e expressões de cortesia afetada devem ser eliminadas da correspondência comercial. Modelos de introduções e fechos de cartas devem ser providenciados para auxiliar as secretárias na redação. Um simples "Cordialmente" será, pois, mais simpático ao destinatário do que todo um parágrafo assim redigido: "Ao ensejo da presente, desejamos consignar a V. Sas. nossos protestos de elevada consideração, profunda estima e distinto aprêço, subscrevendo-nos cordialmente."

- Evitar datilografia supérflua - Obtêm-se considerável economia do tempo gasto em datilografia, e melhor legibilidade, pela omissão de palavras supérfluas em inventários e listas diversas. Na Figura 1, por exemplo, as palavras "cola", "cordão", "correia" etc. poderiam ter sido substituídas por aspas. Deve-se instruir os datilógrafos sôbre o uso correto de abreviaturas normalizadas; escrever $\mathrm{mm}$ no lugar de $\mathrm{m} / \mathrm{m}$ e $\mathrm{g}$ em lugar de gr (Figura 1 ) permite ganhar tempo. O uso de gráficos impõe-se, para maior clareza de leitura e rapidez de execução, no lugar de relatórios como os da Figura 2. Assim é que num relance podem ser vistos no Gráfico 1 os pontos que fogem aos limites de contrôle. 


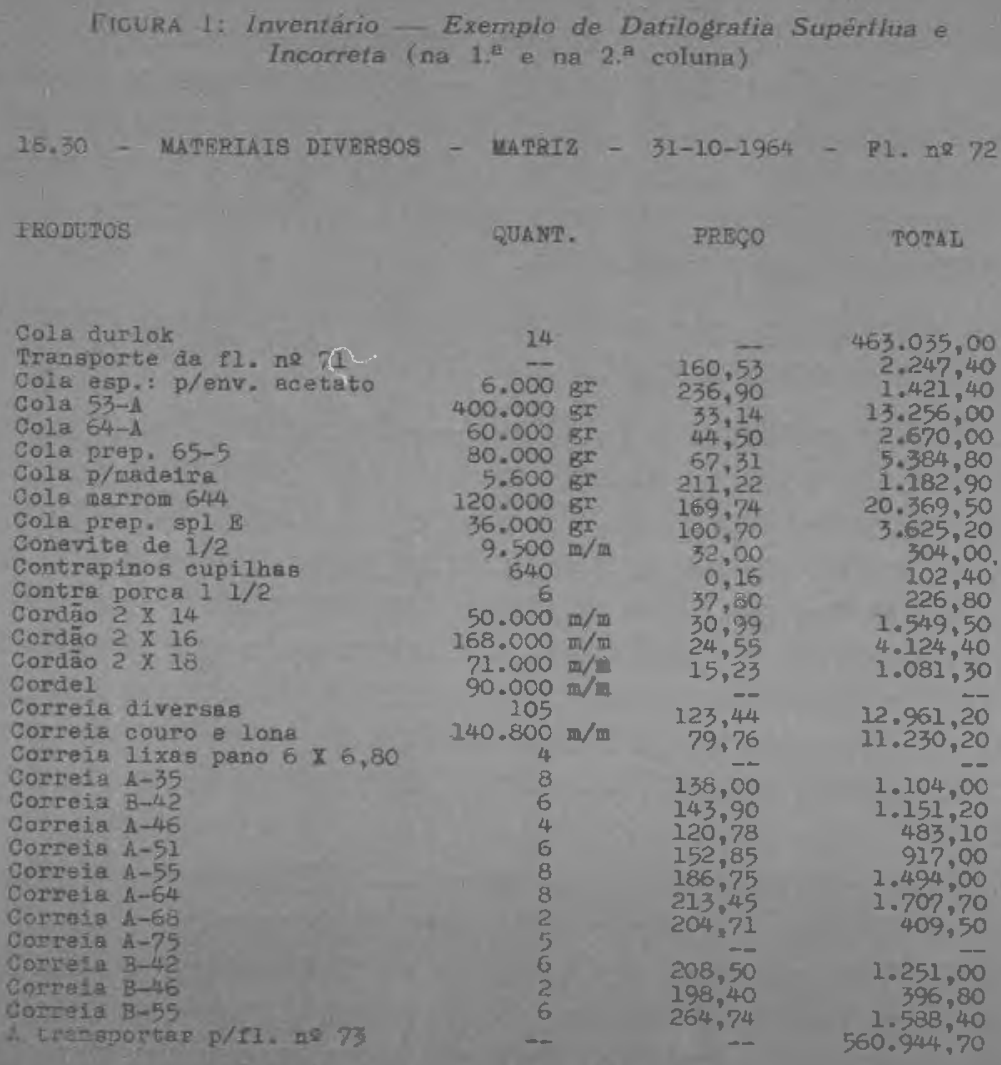




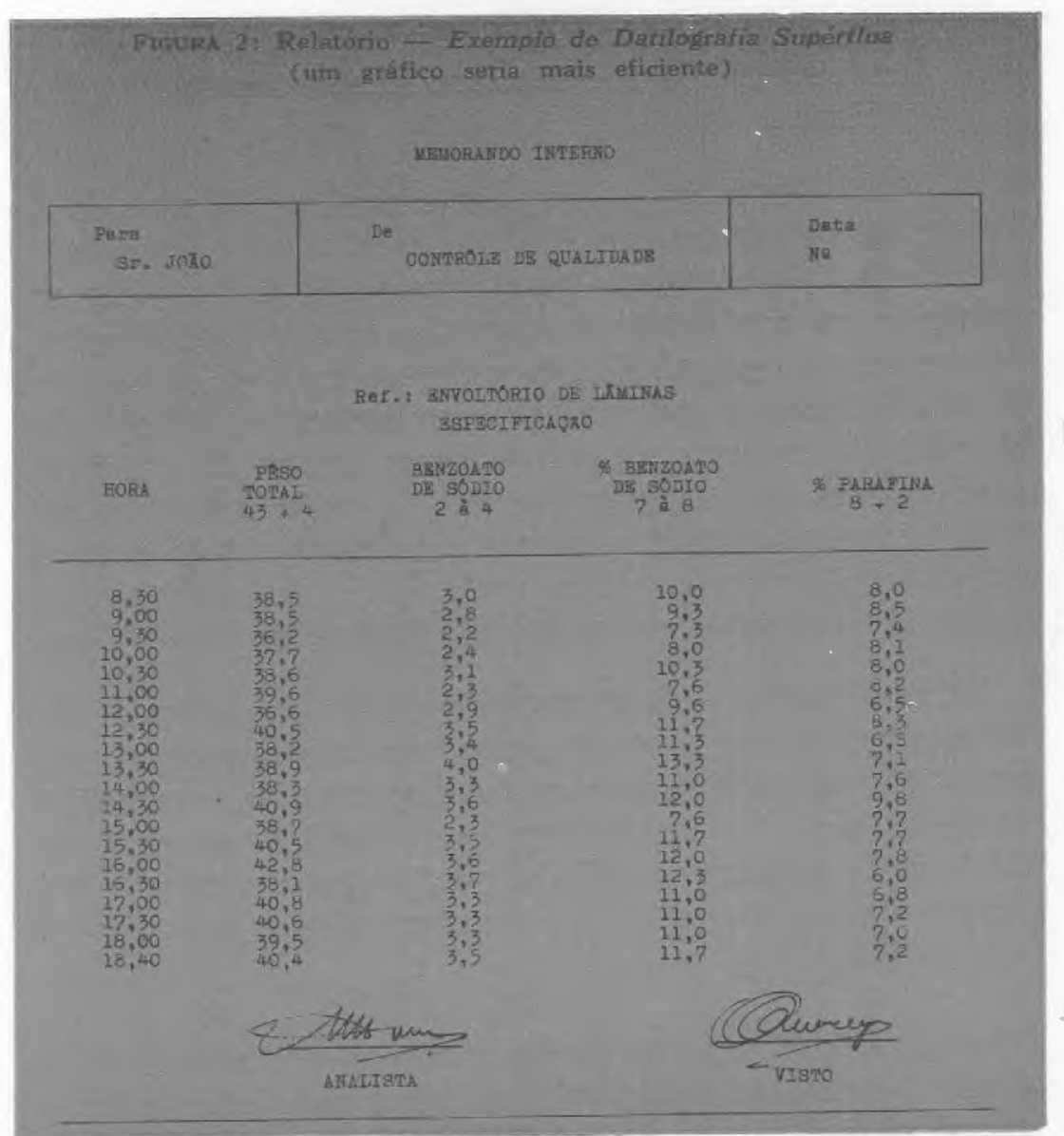

- Arredondar algarismos - Os custos e preços das mercadorias podem ser arredondados. Não tem sentido carregar centavos nas contas, pois o estabelecimento dos custos é baseado em pressupostos e aproximações que invalidam o rigor aparente proporcionado por fraçōes de cruzeiros. Para facilitar os cálculos certas quantidades, como estoques mínimos de itens pouco valiosos, também devem ser arredondados para a dezena de unidades, pois não podem ser determinados com rigor científico.

- Eliminar algarismos supérfluos - Nas notas fiscais (Fig. 3), faturas e relações de estoque omitam-se os zeros 
dos centavos e dos décimos de cruzeiros, usando-se em seu lugar um travessão, a fim de economizar tempo e melhorar a legibilidade.

- Utilizar carimbos - $\mathrm{O}$ uso de carimbos permite ganhar tempo no preenchimento dos documentos e melhorar a legibilidade. Por exemplo, na confecção da legenda dos desenhos técnicos o uso de um carimbo com indicações quanto a nome da emprêsa, data, número da peça, assinatura do projetista etc. permite poupar apreciável tempo dos desenhistas, os quais, de outra forma, teriam de caligrafar êsses dizeres com um normógrafo. A redação de uma editôra melhorou a rapidez do serviço e diminuiu os erros de comunicação com a gráfica, valendo-se de carimbos, em lugar de anotações manuais, nas indicações tipográficas.

- Usar tabelas - As emprêsas que extraem todos os dias notas fiscais compostas de numerosos itens servem-se em geral, de um notista, para efetuar os cálculos e preencher as notas, e de um conferente, para verificar os cálculos . Seria mais econômico utilizar tabelas do que repetir inúmeras vêzes a execução dos mesmos cálculos e conferi-los em seguida.

Tabelas devem ser elaboradas para conversão de medidas de um sistema de unidades para outro, para cálculo de juros, para medição de espaços tipográficos e para inúmeras aplicações comerciais e administrativas.

- Treinar as funcionários na execução das tarefas - Não raro, funcionários de nível modesto encontram dificuldades em efetuar cálculos, embora simples. Por exemplo, no contrôle estatístico de qualidade, ou nas provas de laboratório, o inspetor é chamado a efetuar cômputos da média aritmética das caraterísticas dos cinco elementos da amostra. Sabemos de uma emprêsa em que a divisão por cinco apareceu como obstáculo tão sério que o número de elementos da amostra foi aumentado para 10, por ser considerado mais rápido e seguro medir 10 peças e obter a 
média por simples colocação de uma vírgula na soma, do que medir sòmente cinco peças e fazer a divisão por cinco. Um treinamento sumário dos inspetores teria permitido reduzir pela metade o número de peças inspecionadas, ensinando-se-lhes inclusive como calcular essa média por meio da multiplicação, por dois, da soma dos valôres individuais, seguida da colocação de uma vírgula antes da última casa decimal.

- Determinat locais certos para apor rubricas - Espaço certo deve ser reservado em cada modêlo de formulário para colocação das assinaturas de modo que o recipiendário não precise analisar longamente o documento à procura das rubricas. Essa consideração é válida sobretudo para os papéis que trazem elevado número de vistos.

- Utilizar máquinas de preenchimento de dados - Máquinas de contabilidade efetuam cálculos e extraem notas fiscais, faturas e outros documentos com maior rapidez, exatidão e legibilidade do que os processos manuais .

- Evitar a emissão de cartas e documentos desnecessários - Era costume certa emprêsa distribuidora de produtos alimentícios mandar a seus fregueses, pelo correio, relação dos produtos que lhes estavam sendo enviados, relação essa acompanhada de carta cujos dizeres eram apenas: "Estamos-lhe enviando os produtos cuja relação segue anexa." Essa carta era supérflua; teria sido mais simples escrever os dizeres na própria lista, a mão ou datilografados. Porém, a própria lista era supérflua, pois era a reprodução exata da nota fiscal que acompanhava os produtos! Ademais, os produtos despachados chegavam muito antes da carta, que só era confeccionada, devido à sobrecarga das datilógrafas, dias após a entrega da mercadoria. A supressão de tôda essa correspondência representou simplificação apreciável.

\section{FLUXO DE DOCUMENTOS}

As regras seguintes relativas à circulação dos informes são merecedoras de tôda a atenção por parte dos administradores de sistemas. Essas regras visam a um fim comum: a eliminação de tarefas inúteis . 
- Evitar a duplicação das tarefas - E comum, quando se cria um nôvo departamento, que certas tarefas a êle afetas continuem sendo executadas concomitantemente pelo departamento a que anteriormente sua execução estava atribuida. Assim, por exemplo, a criação de uma seção de pesquisa de mercado não costuma resultar, a menos que se envidem esforços no sentido de definir suas funções, na eliminação imediata de certas tarefas de compilação e análise de vendas, que outras seções - propaganda ou vendas, digamos - desempenharam anteriormente. E freqüente, também, que um dirigente deseje determinada informação e mande um subordinado compilar dados, sem saber que êle poderia ter acesso à mesma informação já calculada por outro departamento, ou sem querer confiar na veracidade dos dados obtidos por outra seção. Em outros casos, certos supervisores querem obter dados em prazo menor do que o geralmente observado pelo setor oficialmente encarregado dêsse cálculo; interceptam, então, o documento, durante sua trajetória, computam o que lhes interessa e, com isso, atrasam mais ainda a obtenção do resultado oficial .

A seção de contabilidade, muitas vêzes, cria um sistema de apuração de custos de matérias-primas, de cálculos de tempo e de apontamento de horas, sem se preocupar com a comunicação dessas informações à seção de produção, a qual, então, terá de criar um sistema independente de recolhimento dêsses dados. Duplicações de tarefas entre contabilidade e vendas, relativamente a cobranças, créditos, cálculos de comissões de vendedores, resultados de vendas etc. não são raras .

Resultados calculados com a mesma finalidade em duas seções diferentes da emprêsa raramente coincidem por causa de divergências nas interpretações, já discutidas acima. Por exemplo: a definição de dois territórios de vendas não será exatamente igual para o departamento de vendas, que usa delimitações empíricas, e para o de pesquisa de mercado, que procura seguir divisões geográficas correspondentes a municípios, estados ou regiões econômicas. No cálculo das vendas mensais o departamento 
de vendas sòmente se interessa pelos resultados provenientes do esfôrço de vendedores, ao passo que a seção de contabilidade incluirá nêle o produto da venda de resíduos e o resultałlo de outras receitas, e descontará dêle as devoluções e abatimentos posteriores à venda. A uniformização das estatísticas de vendas evitará a existência, na emprêsa, de dois jogos de resultados diferentes para as vendas mensais.

Em certa emprêsa o encerramento do ano comercial ocorria em setembro. Na maioria dos departamentos o "1.0 trimestre" de 1963 significava o período compreendido de $1 .^{\circ}$ de outubro a 31 de dezembro de 1962. Mas, o departamento de produção, que garantia o produto por um ano, seguia o calendário habitual. Pode-se imaginar a confusão que essa falta de uniformidade criou nas comunicações interdepartamentais .

Às vêzes é muito difícil ou até impossível eliminar a duplicação de tarefas. Caso freqüente é o do fichário de materiais em estoque, que precisa estar à disposição permanente do almoxarifado e do setor de planejamento de produção, quando não da seção de contabilidade. E preciso muita habilidade para determinar, no caso particular de cada emprêsa, em qual das seções êsse fichário deverá permanecer.

- Eliminar a transcrição de dados - Em certa emprêsa o relatório diário do refugo de uma seção era distribuído a oito dirigentes em oito vias originais. $O$ motivo era 0 receio, por parte da datilógrafa, de que os dirigentes ficassem ofendidos caso recebessem cópias. Entrevistaram-se os oito supervisores: seis declararam que se dariam por satisfeitos com o recebimento de uma cópia; os dois outros explicaram que não necessitavam do documento; de fato, um era chefe de escritório e nada tinha que ver com o objeto do relatório; quanto ao outro, chefiara a seção durante alguns meses, tendo, posteriormente, sido transferido para outra e perdido qualquer interêsse por aquela informação. O relatório passou a ser emitido em uma via original e cinco cópias, economizando-se tempo de datilografia, de distribuição de vias e de arquivamento. 
Em determinada fábrica as requisições ao almoxarifado eram feitas pelos mestres de seção, que rascunhavam no primeiro papelucho que lhes caísse nas mãos os nomes dos materiais que necessitassem; êsse papel era levado ao almoxarife, que entregava os materiais e passava a limpo as requisições. A razão invocada para a existência dêsse estranho sistema era: "os mestres têm mais o que fazer para terem tempo de caligrafar requisições". As conseqüências eram atrasos e erros nas entregas e nas anotações, com o inevitável corolário: "estouros" no fichário de produtos em estoque. Os rascunhos foram suprimidos e os mestres da seção obrigados a se inteirarem exatamente das caraterísticas dos produtos pedidos, e a preencherem os talões de requisições.

Os exemplos mencionados não constituem casos isolados . As transcrições de dados são a doença mais freqüente dos sistemas. E, muitas vêzes, pela erradicação dêsse tumor que convém iniciar o saneamento dos sistemas. As transcrições costumam ser "justificadas" por argumentos os mais diversos; porém, são quase sempre injustificáveis .

Dada a sua frequiência, convém citar mais alguns exemplos típicos de transcrições inúteis .

- Viajantes solicitados a escrever relatórios de vendas semanais não dispõem sempre de máquinas de escrever; devem, pois, escrever seus relatórios de próprio punho. O escritório central, ao receber êsses relatórios, deve lançar diretamente os dados nêles contidos nos gráficos de vendas. Seria êrro passar primeiro êsses relatórios a limpo e usar a transcrição assim obtida para atualizar os gráficos. Sabe-se que as melhores agências de auditoria se referem diretamente às anotações tomadas pelos auditores na emprêsa auditorada, dispensando qualquer datilografia dessas anotações. Os cientistas também confiam mais nas suas notas originais do que nas transcrições ulteriormente feitas.

- As fábricas de produtos químicos se defrontam com um problema na pesagem dos ingredientes que compõem cada carga: a fórmula se encontra registrada no livro de receitas e é retranscrita na ficha de fabricação pelo fun- 
cionário do almoxarifado, responsável pelas pesagens. Para evitar essa transcrição, fonte de erros funestos, seria melhor que a fórmula fôsse mimeografada, podendo o almoxarife riscar cada ingrediente, à medida que êste fôsse pesado e lançado no recipiente onde se efetua a mistura.

- A fim de cada chefe conhecer os nomes dos empregados de certa emprêsa emitia-se mensalmente a relação dos colaboradores, classificados por departamentos e seções. Essa lista era mimeografada em cem exemplares, e êstes eram distribuidos a todos os supervisores. A secretária de um departamento, em vez de utilizar a relação mimeografada, datilografava-a de nôvo. Explicou que assim procedia por motivos de ordem estética: a relação original era "corrida", isto é, os departamentos não constavam forçosamente de páginas separadas. Para isolar os nomes dos membros do departamento seria necessário cortar páginas; funcionalmente, a transcrição era desnecessária e acabou sendo suprimida .

- No processo antigo de extração de carteiras profissionais na Delegacia Regional do Trabalho, de São Paulo, o público apresentava os documentos de identidade a um funcionário que preenchia uma primeira ficha. Outro funcionário transcrevia êsses dados na carteira. Antes da entrega da carteira os dados eram mais uma vez retranscritos num cartão, para arquivamento por lista alfabética .

No processo melhorado os dados são imediatamente passados dos documentos à carteira e transferidos, simultâneamente, por meio de papel-carbono, para o cartão colocado dentro da carteira durante o ato de preenchimento. Pouparam-se assim duas transcrições demoradas e difíceis; e dobrou-se o número de funcionários designados a atender o público.

Há casos em que a transcrição é inevitável: quando, por exemplo, a secretária passa a limpo a correspondência rascunhada pelo seu chefe; quando se redatilografa um artigo para entrega à gráfica, a fim de facilitar, com laudas limpas, o trabalho de composição do linotipista; quando, ainda, é necessário copiar um documento emprestado que por 
qualquer motivo não possa ser reproduzido em Thermo$-F a x$.

- Eliminar listas de conferência - Modalidade comum de transcrição é a lista de conferência. Trata-se de uma relação resumida $B$ (Fig. 4) da informação contida no conjunto de documentos $A$, relação essa que servirá de fonte para a elaboração da informação definitiva $C$.

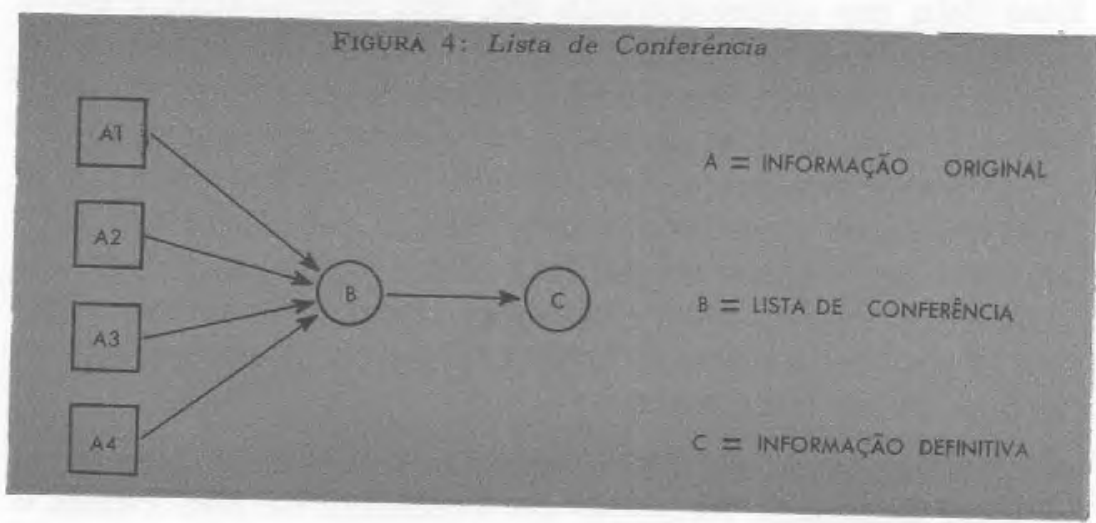

Advoga-se que essas listas:

- possibilitam liberar mais ràpidamente os documentos $A$;

- condensam a informação esparsa dos documentos $A$ em um concentrado $B$, diminuindo, em conseqüência, os erros de cópia de $A$ para $C$.

Para exemplificar citemos o caso seguinte: todos os lotes de produtos acabados que entravam no estoque de certa fábrica era acompanhado de uma ficha $A$ (Fig. 5 ) da qual constavam a data de entrada, o nome do artigo e a quantidade de peças. Essa ficha era visada pelo almoxarife e seguia para o contrôle de estoque. Essa seção era mecanizada: uma operadora perfurava num cartão $C$ de processamento de dados as informações contidas na ficha $A$. A môça cometia numerosos erros, principalmente ao transformar em sinais numéricos codificados para perfuração 
do cartão $C$ os dizeres da ficha $A$. A fim de eliminar êsses erros e tornar mais rápido o processo criou-se a lista intermediária $B$ (Fig. 5-II) na qual eram transcritos os informes contidos nas fichas $A$, e a partir daí eram perfurạdos os cartões $C$.

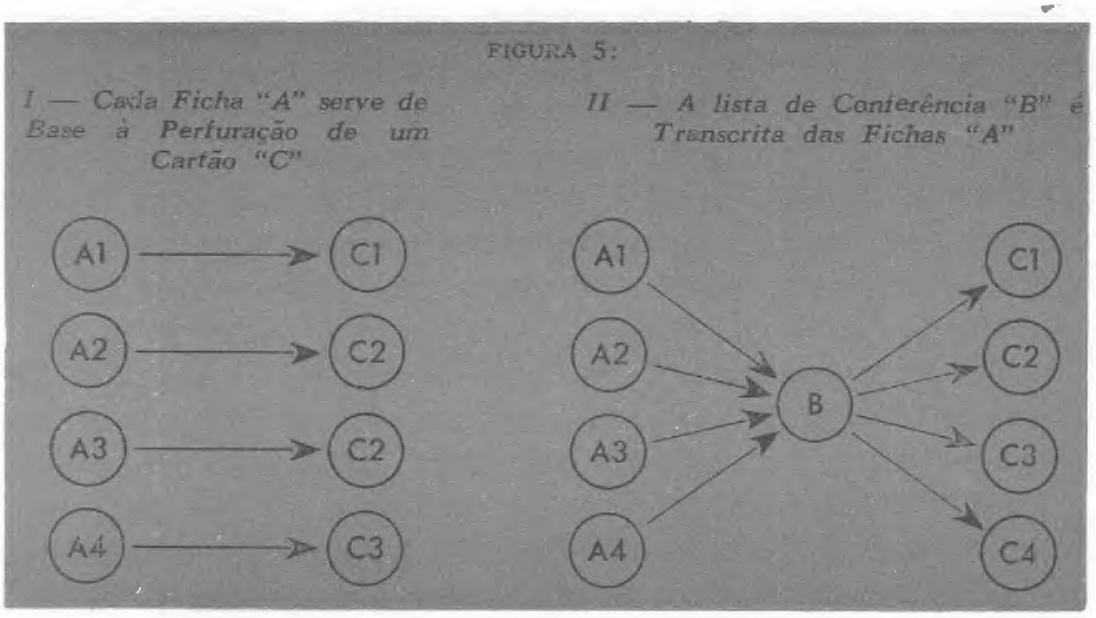

Ao contrário do que se pretendia, essa lista $B$ passou a prender por mais tempo os documentos que ela devia liberar com maior rapidez. Com efeito, ela demorava para ser elaborada e conferida, retendo os documentos que já poderiam ter seguido adiante. Os erros tampouco diminuíram, pois o problema de transformação do nome do produto num número de código, de $B$ para $C$, continuou a existir, agora acrescido de nova fonte potencial de erros, na transcrição de $A$ para $B$. Teria sido melhor ir diretamente à fonte dos erros, selecionando e treinando a perfuradora no uso do código, ou valendo-se de uma verificadora, recurso comum quando se trabalha com cartōes perfurados .

A supressão da lista de conferência permite, pois, em geral, apressar o fluxo das informações e diminuir o número de erros. Vejamos mais dois exemplos.

- Aconteceu em certa emprêsa: um computador eletrônico extraía as notas fiscais da seguinte maneira: os pedi- 
dos dos clientes eram perfurados em cartões, no dia subseqüente ao do seu recebimento; os cartões eram alimentados num computador eletrônico; o computador imprimia as notas fiscais, lançando, pela ordem, o nome, o enderêço, o número de inscrição do freguês e as condições da venda; a seguir, sua memória magnética pesquisava, com grande rapidez, o estoque de cada produto pedido. Quando o produto estava em disponibilidade, o processo terminava nesse ponto. Caso o produto estivesse em falta, o computador interrompia a impressão da nota fiscal e emitia um cartão perfurado que indicava a quantidade em estoque; êsses cartões perfurados, correspondentes aos produtos em falta, eram acumulados ao fim do dia; à base dos cartões fazia-se uma lista de produtos em falta, pedido por pedido, que era entregue ao chefe do depósito de produtos acabados, o qual assinalava na lista, com lápis de côr azul, os produtos que no decorrer do dia haviam dado entrada no depósito; a lista voltava, então, para o computador; um funcionário, baseando-se nos sinais azuis da lista, separava manualmente os cartões relativos a mercadorias já recebidas pelo depósito; as notas fiscais correspondentes a êsses cartões podiam ser agora, finalmente, impressas. Determinou-se que o chefe do depósito de produtos acabados fôsse pessoalmente separar os cartões correspondentes às mercadorias recebidas no dia, suprimindo-se, assim, a lista de conferência e a perda de tempo considerável que representava.

- Ouțra emprêsa desfrutava de isenção do impôsto de consumo para certas matérias-primas, devendo para tanto registrar em livro próprio tôdas as entradas no almoxarifado. No sistema em uso o almoxarife fazia uma relação circunstanciada das mercadorias em questão, contendo números das notas fiscais, preços, quantidades etc.; entregava essa relação, juntamente com as notas fiscais, ao escritu. rário contábil; êste conferia a lista com as notas fiscais, a fim de ver se a lista estava correta e devolvia as notas fiscais ao almoxarife, que as entregava ulteriormente à seção de contas a pagar. O escriturário contábil transcrevia, então, no livro fiscal os informes contidos na lista. Observe-se que a finalidade da lista de conferência era per- 
mitir ao escriturário contábil lançar os dados no livro fiscal sem precisar reter por muito tempo as notas fiscais, a fim de que estas pudessem seguir ràpidamente para a seção de contas a pagar. O tempo que se perdia na confecção da lista e na sua conferência poderia ser usado para o lançamento direto das notas fiscais no livro, sem o intermédio da lista, solução que foi posteriormente adotada.

Listas de conferência não devem ser confundidas com relações cuja finalidade seja indicar que um número determinado de documentos está sendo entregue. Assim, no caso precedente, um curtíssimo memorando que dissessè, simplesmente, " $x$ notas fiscais neste maço" seria suficiente para assinalar, através de uma contagem rápida na seção contábil, que alguma nota fiscal fôra extraviada na sua vinda do almoxarifado.

- Uma editôra tem de entregar à seção de gráfica, mensalmente, todo o material redacional de uma revista; êste é muito heterogêneo, consistindo numa série de matérias, reportagens, artigos, seções permanentes etc. . Cada matéria segue num envelope, no qual são colocados o texto original datilografado, os títulos em fototipo, os gráficos, as fotos e os diagramas que esquematizam a paginação. Mandar êsse material sem nenhuma relação de conferência dá azo a extravios; por outro lado, uma relação muito pormenorizada consome muito tempo na elaboração e na conferência. A solução preferível é informar, simplesmente, para cada matéria, que seguem tantas páginas de texto, tantos gráficos, tantas fotos etc. .

- Suprimir assinaturas supérfluas - A aposição de assinaturas em documentos administrativos constitui, com freqüência, mera formalidade. A longa imobilização de um sistema à espera do visto de um diretor que aprova automàticamente o documento, sem se inteirar do seu conteúdo, resulta da tradição de que tôdas as comunicações devem vir de cima para baixo na escala hierárquica da organização. A diretoria quer ler tôda a correspondência expedida ou respondida. E, quando reina desconfiança entre os diretores, todos êles querem ler a correspondência de qualquer natureza . 
Em certa emprêsa os pedidos dos clientes eram visados por cinco diretores antes de ir para o cadastro; o resultado é que vários dias passavam entre a entrada do pedido e o seu processamento. Dias preciosos, que representavam tempo perdido para a produção.

A exigência de que o diretor-tesoureiro assine cada pedido de compra é descabida quando a importância é pequena, principalmente se a compra já tiver sido aprovada nos orçamentos de compras e desembolsos.

Em serviços de rotina os vistos devem ser delegados aos subordinados; o superior deve aprovar sòmente documentos de caráter não rotineiro. A aplicação dêsse "princípio de exceção" permite poupar o tempo do superior para atividades de maior importância.

- Suprimir cópias inúteis - E indispensável eliminar as cópias inúteis dos sistemas, isto é, as cópias que não serão consultadas por nenhum interessado. Sua supressão resulta em economia de tempo, material e espaço; evita que se divulguem informações reservadas; força os funcionários a efetuarem as operações com cuidado, por não disporem de cópias particulares para conferir dúvidas. A circulação de uma via única é, muitas vêzes, preferível à emissão de u'a multidão de cópias .

- Restringit ao mínimo os protocolos - Protocolo é o comprovante da entrega de um documento. Pode consistir:

- em lançamento por seqüência numérica num livro de registro, sendo o documento carimbado com igual número;

- em assinatura aposta pelo recipiendário na segunda via do documento, a qual fica em poder do emitente;

- em documento-recibo.

Os dois primeiros métodos são preferíveis, pois evitam a criação de um documento.

Justifica-se a existência de protocolos internos nas emprêsas quando êles contribuem: 
- para evitar atrasos e extravios de documentos; o recipiendário despachará mais ràpidamente um documento se a sua responsabilidade estiver registrada num protocolo;

- para permitir acompanhar o trâmite do documento. Por exemplo: os pedidos de fregueses têm de passar sucessivamente pelas seções de vendas, cadastro, contrôle de estoque, extração de notas fiscais, embalagem, armazém e, finalmente, expedição. Se um cliente telefonar indagando do seu pedido, a existência de um livro de registro de pedidos e de um livro de protocolo permitirá à seção de vendas localizar ràpidamente o pedido e informar o freguês da data final provável do aviamento. Um único livro de protocolo, judiciosamente situado num ponto crítico do sistema, será suficiente, não se devendo criar livros desnecessários em tôdas as etapas.

- Melhorar o arranjo físico - A rapidez e a exatidão dé processamento do sistema podem ser facilitadas pela disposição racional das máquinas, mesas e seções. Foi assim que numa fábrica o deslocamento do notista da seção contábil para o armazém de produtos acabados permitiu apressar a extração de notas fiscais e a conferência das mercadorias despachadas. Noutro caso o deslocamento da seção de planejamento de produção para junto do almoxarifado permitiu eliminar a duplicação do arquivo de matérias-primas.

- Simplificar os movimentos - Deve-se procurar simplificar os movimentos nas operações rotineiras de escritório. Carimbos; cartas com margens, cabeçalhos, marcas de dobras e outras indicações já impressas; cartas-envelopes; dispositivos para classificar cópias, e um sem número de engenhosos recursos precisam ser utilizados pelo administrador a fim de racionalizar os sistemas.

- Tornar o sistema automático - Quando o sistema é automático ganha-se tempo de supervisão e de operação. Ređuzem-se ao mínimo as hesitações e os erros. A mecanização dos sistemas e o uso de aparelhos de processamento de dados contribuem para automatizar as rotinas. 
- Distribuir instruções escritas - A delegação de funções e a especificação das rotinas devem ser escritas e distribuídas aos funcionários. A existência de instruções escritas fixa as responsabilidades, evita enganos e ajuda a treinar funcionários.

\section{REPRESENTAÇĀO GRÁFICA DOS SISTEMAS}

Para analisar o fluxo dos documentos convém lançar mão de representações gráficas; os fluxogramas proporcionam melhor visualização do trâmite minucioso de todos os documentos num sistema, por mais complexo que seja.

Existem muitos processos de representação gráfica dos sistemas; apenas um dos mais simples — porém, dos mais eficientes - será ilustrado aqui. Consiste em dividir uma fôlha de papel em colunas (cada uma das quais representa un funcionário ou uma seção) e em linhas (cada uma das quais corresponde a uma etapa do processo). O trajeto de cada via dos documentos é representado por linhas de traço cheio; o movimento de materiais ou pessoas é representado por linhas pontilhadas, traços mais grossos, ou outra convenção qualquer. Os símbolos constantes da Figura 6 são usados para descrever as atividades fundamentais.

FIGURA 6: Símbolos Convencionais para Representação Gráfica de Sistemas

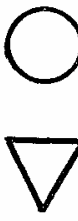

OPERAÇÃO

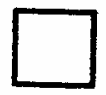

INSPEÇÃO

ARQUIVAMENTO

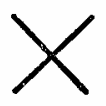

DESTRUIÇÃO

TRANSPORTE

- Uma operação é realizada quando algo é criado, alterado, acrescentado ou subtraído. Exemplos de operação: emissão de urn documento, aposição de uma assinatura ou de um carimbo, separação de vias, grampeamento. 
- O arquivamento pode ser temporário ou permanente, sôbre u'a mesa, numa gaveta ou num arquivo .

- Um transporte ocorre quando um funcionário, um objeto, uma mensagem ou um documento é movimentado de um local para outro. Para maior clareza são omitidos dos fluxogramas de documentos os símbolos correspondentes a transportes de curta distância e a transferência de mesa a mesa.

- Inspeção é a verificação ou fiscalização, sem realização de operações. Exemplos de inspeção: leitura de um documento, conferência de cálculos, verificação de uma lista de mercadorias.

- Destruição é a eliminação física do documento.

Quando, num pôsto de trabalho, uma inspeção é realizada antes ou depois de uma operação pode-se omitir o símbolo da inspeção. Os mensageiros, a recepção e outros pormenores são freqüentemente omitidos dos fluxogramas. À esquerda do fluxograma, a coluna de maior largura é utilizada para descrever as etapas do procedimento. Os arquivamentos não costumam ser descritos, nem se reserva linha especial para êles. Colunas acessórias são utilizadas para indicar as distâncias percorridas e os tempos consumidos na realização das etapas. Um resumo do número de operações, inspeções, arquivamentos e documentos usados é efetuado na parte inferior do fluxograma.

EXEMPLO DE RACIONALIZAÇÃO DE UM SISTEMA

Para ilustrar o uso de fluxogramas escolhemos um sistema relativamente simples. O fluxograma da Figura 7 descreve o sistema de correspondência usado por uma emprêsa entre a matriz e as filiais. Exemplifica o caso de uma instrução emitida pelo diretor de pessoal e destinada aos gerentes de pessoal das filiais. As etapas essenciais do processo são as seguintes:

1) $O$ diretor de pessoal escreve a carta-instrução. 
2) 0 diretor de vendas corrige a carta, a fim de que ela não entre em conflito com o regulamento interno do seu departamento e seja perfeitamente aceitável pelos gerentes locais das filiais, que lhe são diretamente subordinados e cujas peculiaridades êle conhece.

3) A carta é datilografada em cinco vias para cada gerente de filial. A $1 .^{a}$ via é mandada ao gerente, por serviço de

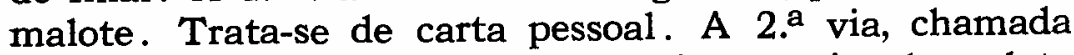
"confirmativa", é mandada pelo próximo serviço de malote e é destruída pelo gerente de filial quando êste já recebeu a $1 .^{\text {a }}$ via. A $3 .^{\text {a }}$ via permanece no arquivo pessoal do diretor de vendas. A $4 .^{a}$ via é arquivada pela funcionária da vigilância, que acompanha o movimento de tôda a correspondência e reclama quando há atraso nas respostas. A $5 .^{a}$ via é guardada pela secretária no arquivo do departamento de vendas.

4) $O$ gerente de filial recebe a carta e se inteira dos seus dizeres.

5) A secretária do gerente de filial transcreve a carta para o gerente de pessoal da filial.

6) O gerente de pessoal da filial inteira-se da instrução.

7) O gerente de filial destrói a via confirmativa .

8) A vigilância destrói a $4 .^{a}$ via quando recebe resposta da filial que confirme a recepção da instrução.

As etapas da rotina modificada, representadas na Figura 8, eram as seguintes:

1) 0 diretor do departamento do pessoal auxiliava o diretor de vendas a redigir a instrução.

2) A secretária do departamento de vendas mimeografava a instrução; mandava duas vias a cada gerente de filial, sendo uma delas destinada ao gerente de pessoal local; conservava uma via $\left(3 .^{a}\right)$ no seu arquivo e mandava um exemplar ao diretor de pessoal.

3) O gerente de filial se inteirava da circular e arquivava sua cópia. 
FIgURA 7: Sistema Antigo de Cortespondência com Filiais

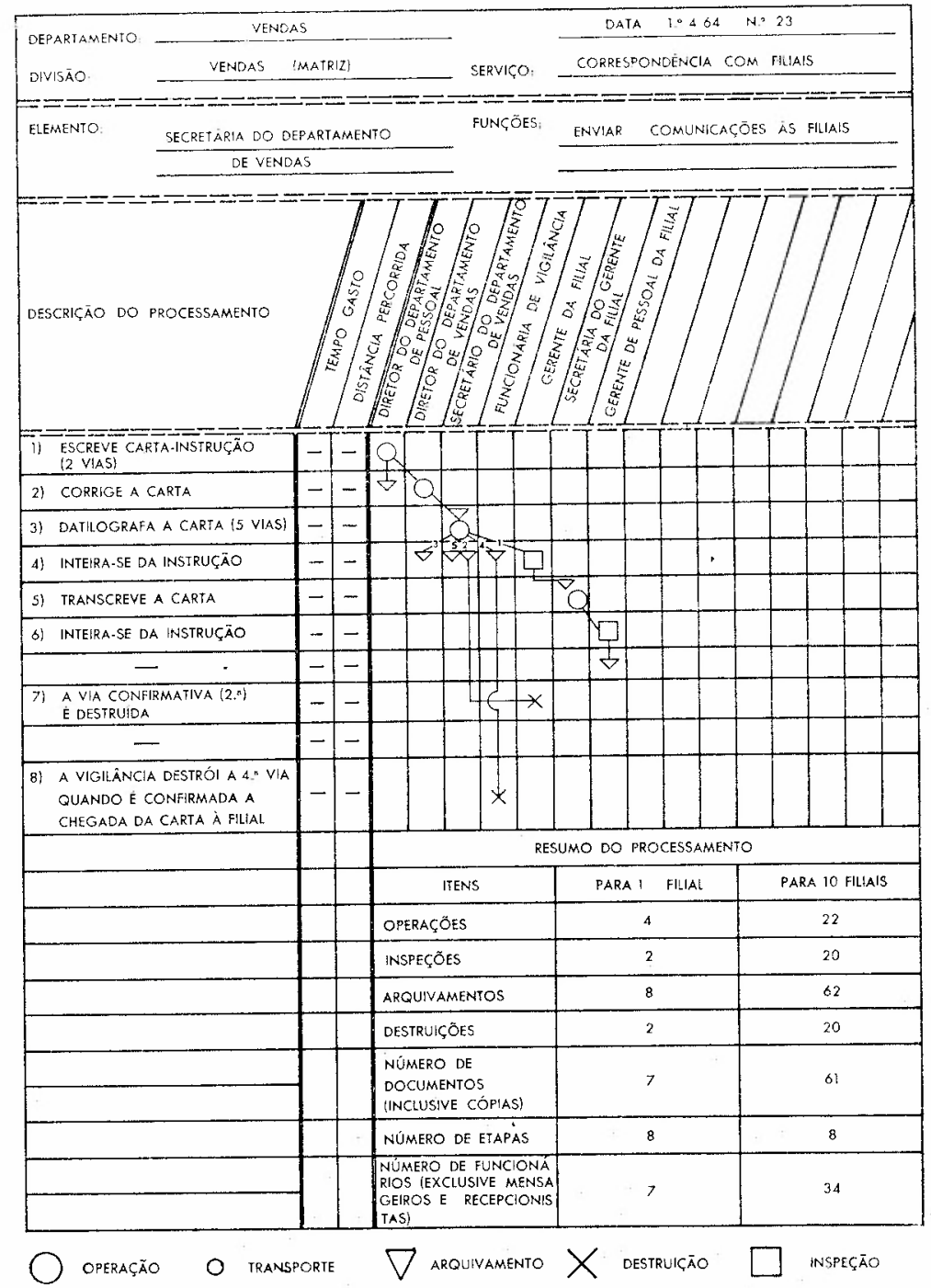


4) O gerente de pessoal da filial inteirava-se da circular e arquivava sua cópia.

As maiores modificações foram estas:

- As cartas pessoais aos gerentes de filiais foram transformadas em instruções-circulares, mimeografadas .

- A via confirmativa foi suprimida; era extremamente raro o extravio de cartas pelo sistema de malotes; era preferível correr o risco calculaido de um extravio ocasional a ter certeza do considerável trabalho suplementar ocasionado pela via confirmativa.

- A vigilância passou a ser desempenhada pela própria secretária, pois o seu trabalho de datilografia ficou sensìvelmente reduzido.

O sistema ficou apreciàvelmente simplificado: levando-se em conta que existiam dez filiais, reduziram-se a 3 as 22 atividades; a 23 os 62 arquivamentos; a nenhuma as 20 destruições; a 24 os 61 documentos; a 4 as 8 etapas.

\section{ARQUIVAMENTO DOS DOCUMENTOS}

Após um período de vida ativa os documentos são recolhidos num arquivo; devem ser conservados e classificados de maneira que possam ser fàcilmente encontrados. Após alguns meses ou anos o documento perde a sua atualidade e segue para o "cemitério dos documentos", o arquivo morto. Serão conservados ali por alguns anos, até que seja decidida sua destruição final.

$O$ arquivo vivo é quase sempre constituído de fichários de aço, com pastas verticais suspensas, permitindo o encontro rápido do documento. Livros e cartões podem ser guardados em prateleiras. Os mapas e desenhos serão guardados em mapotecas, horizontalmente, classificados por formatos padronizados.

No arquivo morto o môfo, a umidade, a poeira, os insetos e os roedores constituem inimigos contra os quais é preciso usar caixas ou armários adequados, providos de ventilação e tratados com inseticidas. 
Para facilitar a consulta rápida os documentos serão classificados, no arquivo morto, por ano, departamento e natureza. $O$ conteúdo será claramente indicado no invólucro externo. Tôdas as caixas ou armários devem ser de fácil acesso. As pastas de papelão e outros materiais de escritório recuperáveis deverão ser separados e repostos em circulação. Picar os documentos, quando de sua destruição definitiva, e vendê-los como papel velho é prefível a incinerá-los.

Cada departamento deverá decidir quanto ao tempo de conservação de seus documentos no arquivo morto; sòmente o departamento de pesquisas de mercado sabe 0 tempo desejável para a preservação de suas pesquisas. Porém, os documentos deverão ser guardados até, pelo menos, o vencimento dos prazos de prescrição, que no Brasil são os seguintes, de acôrdo com os Códigos Civil e Comercial:

- Documentos relativos a institutos de previdência e a legislação social do trabalho ..

30 anos

- Documentos relativos a obrigações pessoais e liquidações de obrigações pessoais ....

20 anos

- Documentos relativos a obrigações comerciais (comprovantes de pagamento de impostos de renda, sêlo, consumo, vendas $e$ consignações; duplicatas e outros títulos de crédito; notas fiscais, recibos, contratos, alvarás, faturas, livros fiscais, livros contábeis etc.) $\ldots \ldots \ldots \ldots \ldots \ldots \ldots$

5 anos

\section{CONCLUSÃO}

O estudo dos sistemas tem sido negligenciado pelos administradores. Entretanto, sua racionalização permite grandes economias, suprimindo-se fichas e tarefas desnecessárias e tornando-se mais rápida e exata a transmissão das informações. Nosso intuito neste artigo foi fornecer ao administrador uma série de fios condutores que o ajudem a desvendar as tramas, por vêzes complexas, dos sistemas. 
Figura 8: Sistema Nôvo de Correspondência com Filiais

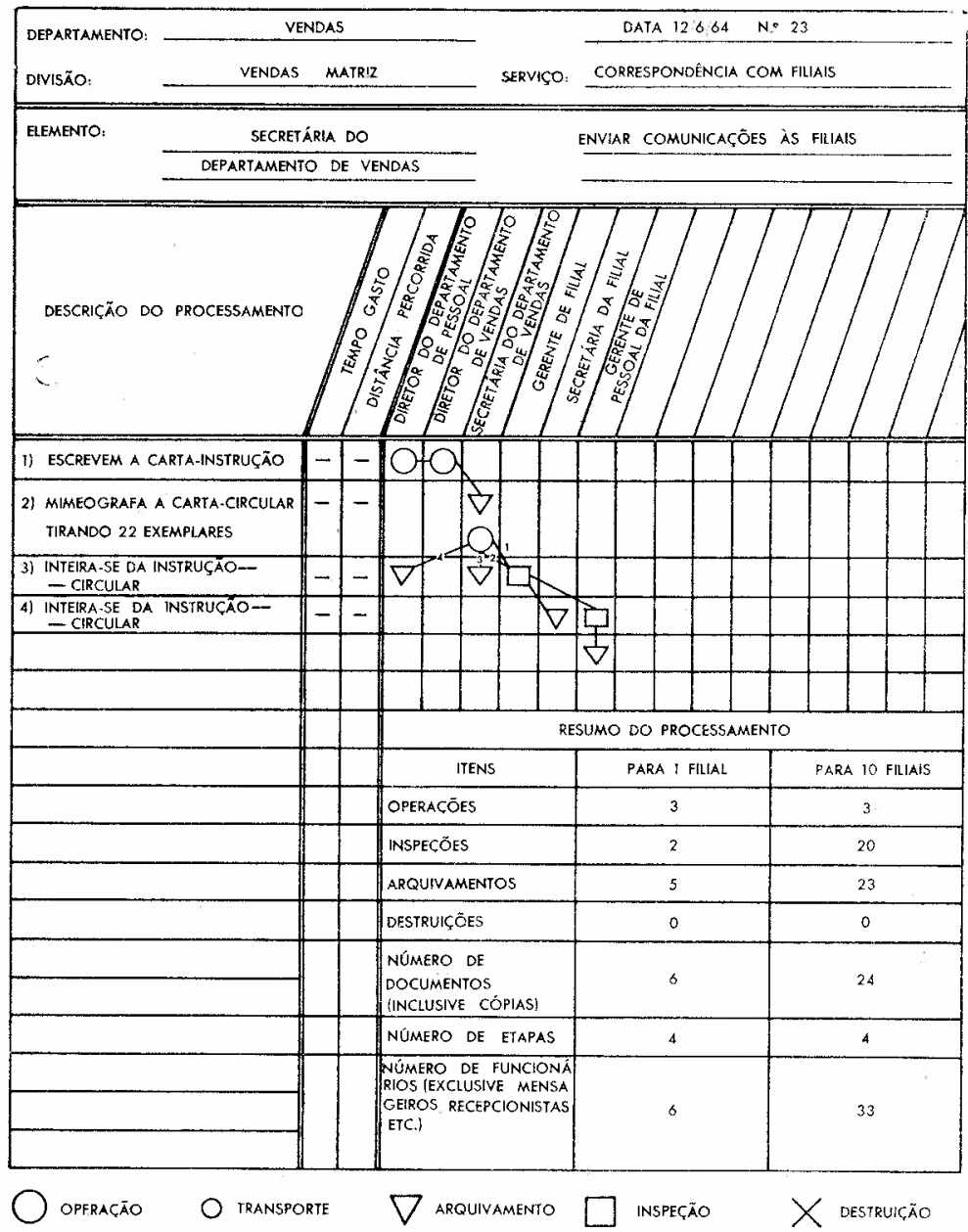

Outros aspectos - cujo estudo ultrapassaria os limites de um artigo - foram deixados de lado; por exemplo, a utilização de gráficos mais pormenorizados, a teoria e o uso de equipamento de impressão e de máquinas de processamento de dados.

A ascenção, a maturidade e a decadência das emprêsas são marcadas por fases burocráticas: quando de seus pri- 
mórdios, quase não existem formulários; o dinamismo e o interêsse fazem com que todos os informes sejam transmitidos verbalmente, sem esquecimento nem atraso. Ao atingir seu apogeu a emprêsa conta com quantidade certa de papéis, o que permite a transmissão e o contrôle das informações, com o máximo de eficiência. Nos períodos de declínio proliferam formulários supérfluos, mas a sobreabundância de documentos não consegue suprir a falta de entusiasmo nem despertar o senso de responsabilidade, nem tampouco controlar os desempenhos vacilantes.

A palavra "burocrata" suscita considerável menosprêzo. O estigma associado ao homem que lida com papéis, em oposição ao que trabalha na produção, provém da crença de que o papel, no fundo, é inútil, em nada contribuindo para a criação da riqueza. O burocrata é visto como um intermediário que prejudica o livre trânsito das informações. Se as "rotinas" são inúteis e complexas, o burocrata merece ser criticado; na medida, porém, em que, qual incansável Argos, êle vigia diligentemente a multidão de impressos, elimina as excrescências parasitárias que, como as cabeças de uma hidra, tentam sufocar a emprêsa, e, finalmente, cria instrumentos de planejamento, contrôle e transmissão de informações, sem as quais a emprêsa seria acéfala, o burocrata é elemento vital na luta pela melhoria da produtividade.

\section{BIBLIOGRAFIA}

ANTon Dakitsch, Padronização de Papéis em Geral, Rio de Janeiro: Biblioteca de Ensino Industrial, CBAI, Ministério da Educação e Saúde, 1950.

Frank M. KNox, Design and Control of Business, Forms, Nova Ictqué: McGraw-Hill Book Co., 1952.

HARRY L. WYLIE, Office Organization and Management, Englewood Cliffs: Prentice Hall Inc., 3. ${ }^{a}$ edição, 1953.

John J. W. Neuner e Benjamin R. HAynes, Office Management and Practices, Cincinatti: South Western Publishing Co., 1947.

Norman N. BARISH, System Analysis, Nova Iorque: Funk Wagnalls Co., 1951. Victor Lazzaro, Systems and Procedures, Englewcod Cliffs: Prentice Hall Inc., 1959. 